\title{
The Evaluation of Epoxy Resin Coated Quartz Crystal Humidity Sensor and the Measurement of Water Evaporation from Human Surfaces
}

\author{
Koji ENDO*, Noboru SUZUKI**, Masato HOSHI*, Yasushi SHIOYA*, \\ Teiji KATO** and Yoshiaki FUJIKURA*
}

\author{
*Analytical Research Center, KAO Corporation (2606, Akabane, Ichikai-machi, Haga-gun, Tochigi 321-3497) \\ ** Graduate School of Engineering, Utsunomiya University (7-1-2, Yoto, Utsunomiya-shi, Tochigi 321-8585)
}

\begin{abstract}
A highly sensitive humidity sensor was prepared by the coating of epoxy resin on a quartz crystal sensor surface. The probe was adapted to a ventilated chamber-type apparatus for the measurement of water evaporation from human surfaces. In the range from 0 to $50 \%$ relative humidity $(\mathrm{RH})$, the relationship between $\mathrm{RH}$ and resonant frequency showed good linearity with high resolution, $\leq 0.1 \% \mathrm{RH}$. By alternation between standard air $(10 \% \mathrm{RH})$ and humidified air $(12.5,22.5,32.5 \% \mathrm{RH})$, the time to reach steady state was determined to be less than 120 sec for both absorption and desorption processes. The frequency at the steady state was very stable.

This newly developed humidity sensor was used to measure water evaporation rates from human forearm, cheek, palm of hand and ocular surface. The observed rates were $10.7 \pm 0.5,35.0 \pm 1.3,40.2 \pm 1.6$ and $298.9 \pm 4.0 \mathrm{~g} / \mathrm{m}^{2} \cdot \mathrm{hr}$ (mean \pm standard deviation) respectively. These values and regional differences were consistent with those previously reported. The sensitivity and responsiveness of the new probe was best seen when measuring evaporation from the ocular surface. After achieving steady state, oscillations of the resonant frequency coincided with blinks of the eye at $5 \mathrm{sec}$ intervals. Therefore, this new system that utilizes an epoxy-coated quartz crystal sensor will very useful to evaluate dynamic changes of water evaporation rate. It may have both clinical and industrial uses.
\end{abstract}

Key Words : Ventilated Chamber System, Skin, Ocular Surface, Blink

\section{Introduction}

Skin possesses a barrier function that protects the body from desiccation. The effectiveness of the skin as a permeability barrier is determined by the rate of water evaporation from the surface. Two methods, one utilizing an evaporimeter ${ }^{1)}$ and the other a ventilated chamber $^{2)}$, have been used to measure the rate of evaporation. The evaporimeter measures the gradient of water vapor pressure close to the skin surface and depends upon two hygrometers at fixed points perpendicular to the surface in the zone of diffusion. In contrast, the ventilated chamber method determines the rate of water evaporation based upon the difference in vapor pressure between outlet and inlet gases that pass continuously through the measuring chamber at a predetermined flow rate.

The AT-cut quartz crystal microbalance (QCM) has high sensitivity to mass changes on the surface. Therefore, if the coating film formed on the surface of the quartz crystal has reasonable adsorption-desorption properties, the concentration of water vapor can be easily measured by detecting a shift in resonant frequency. Various coatings have been investigated to develop a humidity sensor by application of QCM technology. In 1964, King demonstrated that a coated quartz crystal could be used as a sorption detector for water using silica gel, molecular sieves, alumina and hygros- copic polymers ${ }^{3,4)}$. In recent years, many coating materials, including fluorides and oxides ${ }^{5}$, ethylene glycol $^{6}$, gelatin $^{7)}$, and others ${ }^{8 / 17)}$ have been studied. Desirable properties of the coating material are high sensitivity with a linear response over a wide humidity range, short response time, high stability and simple coating method.

With the ventilated chamber method for determination of evaporation rates, dry air or $\mathrm{N}_{2}$ gas is used as a carrier gas; therefore, it is important to develop a humidity sensor with the properties described above, particularly in the low relative humidity (RH) range. Epoxy resin is a readily available and inexpensive material that has high sensitivity with a linear response over a wide humidity range ${ }^{9), 10}$. It adheres to substrate firmly and the coating method is simple. Moreover, it has superior thermal stability and mechanical strength and good stability to chemicals. For these reasons, epoxy resin was selected out of several good commercially available water sorbents and was evaluated as a coating material for quartz crystal humidity sensor in the low $\mathrm{RH}$ range.

For this study we developed a ventilated chamber system that utilizes epoxy-coated quartz crystal technology for the rapid and high precision measurement of water evaporation rates from the skin. Because the rate of water evaporation from skin is very small, approximately $5-30 \mathrm{~g} / \mathrm{m}^{2} \cdot \mathrm{hr}$, the new system was designed to detect small changes in short time periods. The appara- 
tus is suitable for use in the laboratory and clinic. Additionally, we adapted our system to measure the rate of water evaporation from the preocular tear film that covers the surface of the eye. The tear film is particularly important because the moist surface of the eye is exposed to the atmosphere, and high evaporation rates are associated with dry eye syndromes ${ }^{18)}$. Thus it is important to develop methods for assessing the rate of evaporation from both healthy and diseased eyes.

\section{Exprimental}

\section{1 Quartz crystal sensor}

A $9 \mathrm{MHz}$ AT-cut quartz crystal with $8 \mathrm{~mm}$ diameter and $0.2 \mathrm{~mm}$ thickness was used in this study. The sensor surface was coated with epoxy resin by dip coating. The resin was prepared as a $10 \%$ acetone solution (by weight) and mixed with an equal volume of $10 \%$ polyamide resin hardener (Araldite ${ }^{\circledR}$ rapid, Ciba-Geigy Co., Switzerland) in acetone to form the dip coating. Polymerization was carried out at room temperature for $24 \mathrm{~h}$. Unreacted components on the coating were removed by a $1 \mathrm{~min}$ wash in acetone.

If the mass of the epoxy coating applied to the quartz crystal does not exceed $2 \%$ of the mass of the crystal alone, then the mass of the coating can be considered to be the same as the mass of an equivalent thickness of quartz (Sauerbrey equation) ${ }^{19)}$. When a uniform layer of a foreign material, such as water vapor molecules, is deposited on the epoxy-coated quartz surface, the change of output frequency is described by the following equation :

$$
\Delta F=-2.3 \cdot 10^{6} \cdot F_{0}{ }^{2} \cdot \Delta m / A_{q}
$$

where $\Delta F$ is the frequency shift $(\mathrm{Hz}), F_{0}$ is the frequency of bare quartz crystal $(\mathrm{MHz}), A_{q}$ is the piezoelectrically active area $\left(\mathrm{cm}^{2}\right)$ and $\Delta m$ is the change in the mass of the film ( $\mathrm{g}$ ) due to adsorption of water vapor. While changes in viscosity and/or elasticity of the film on quartz crystal can affect the resonant frequency ${ }^{20,21)}$, it is assumed that those properties are not changed by water vapor deposition on the film because the adsorbed amount is very small.

\section{2 Apparatus set-up and measurements}

The experimental set-up of the apparatus includes a gas-introductory path attached at the sidewall portion of the main body (Figure 1). An inlet gas, the water content of which is predetermined, is fed to the skin surface through the path. A slide-plate type shutter is located close to the bottom of chamber and can be opened to expose the skin to the carrier gas. The resonant frequency of the quartz crystal is measured by a frequency counter (Model 53132 A, Agilent Technologies Inc., California, USA) every $0.5 \mathrm{sec}$ and the data are collected and processed by a personal computer.

For the evaluation of the resonant frequency dependence on humidity, experiments were conducted in a constant temperature room. The RH of the inlet gas was adjusted using mass flow meters (Model 3660, Kofloc Inc., Tokyo, Japan) to mix humidified and dry gases in appropriate ratios (Figure 2). The flow rate was set at $250 \mathrm{ml} / \mathrm{min}$. The $\mathrm{RH}$ and temperature of the mixture

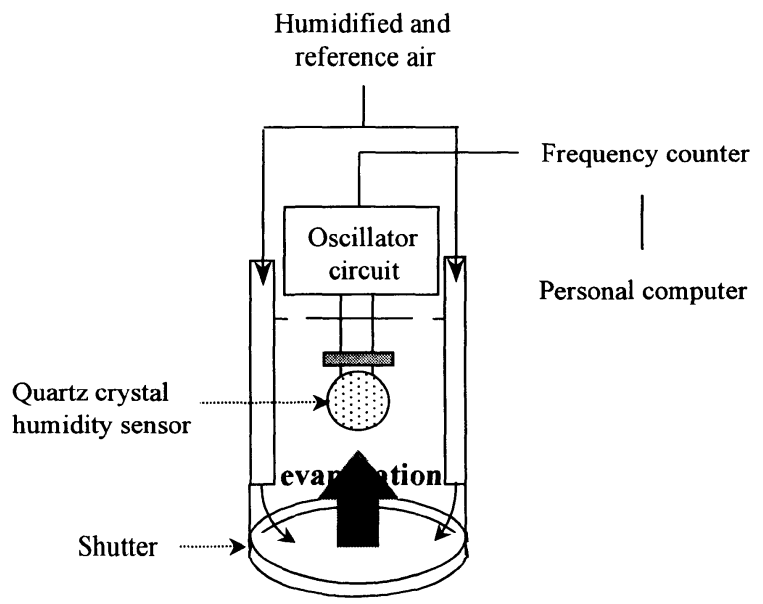

Fig. 1 Schematic illustration of the probe to measure water evaporation from skin and ocular surfaces.

The associated air resource, frequency counter and personal computer are also shown. The probe is housed in a stainless steel cylinder with an inner diameter of $2 \mathrm{~cm}$ and a height of $4 \mathrm{~cm}$.

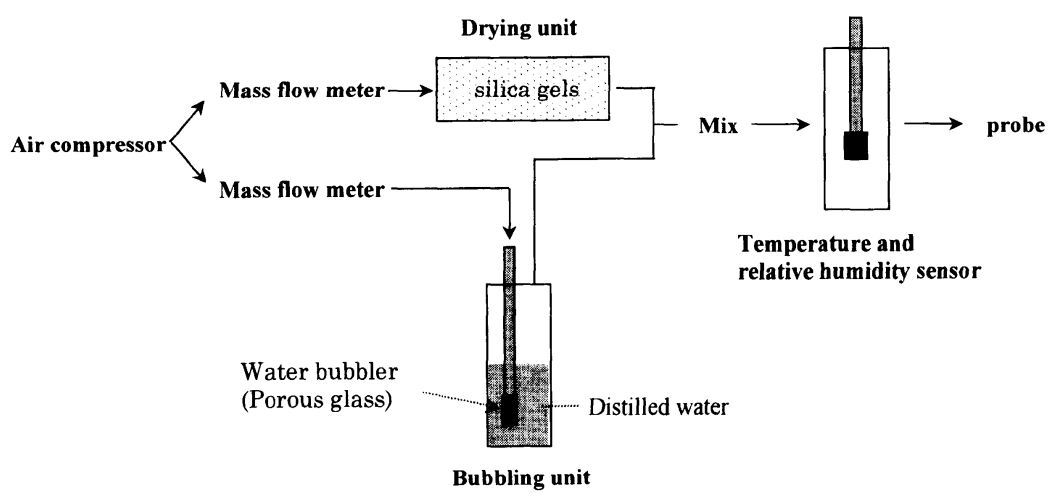

Fig. 2 Schematic diagram of the air resource.

Humidified air is generated by bubbling compressed air through a porous glass bubbler in distilled water. Dry air is obtained by passage through a drying unit $(40 \times 70 \mathrm{~mm})$ containing silica gel. The humidified and dried air streams are mixed before passage to the probe. 
were precisely predetermined by a temperaturehumidity sensor (Model 645, testo $\mathrm{GmbH} \&$ Co., Lenzkirch, Germany) with an accuracy of $\pm 2 \%$.

Measurements of water evaporation rates from skin and ocular surfaces were carried out in a room at $20^{\circ} \mathrm{C}$, $40 \% \mathrm{RH}$, and a flow rate of $250 \mathrm{ml} / \mathrm{min}$ for the dry air carrier gas. For skin evaporation rates, the measuring area was $3.2 \mathrm{~cm}^{2}$. For ocular surface evaporation rates, the probe was fitted to a goggle with a measuring area of $13.8 \mathrm{~cm}^{2}$ and placed over the eye to achieve stable readings.

The difference in relative humidity between the outlet and inlet gas, $\Delta H(\%)$, was determined by the quartz crystal humidity sensor, and the rates of water evaporation from skin, $J\left(\mathrm{~g} / \mathrm{m}^{2} \cdot \mathrm{hr}\right)$, were calculated using the following equation :

$$
J=\frac{1}{A} \frac{\Delta H}{100} \rho V
$$

where $A$ is the measuring area $\left(\mathrm{m}^{2}\right), \rho$ is the water content $\left(\mathrm{g} / \mathrm{m}^{3}\right)$ of the air having $100 \% \mathrm{RH}$ at a given temperature, and $V$ is the gas flow rate $\left(\mathrm{m}^{3} / \mathrm{hr}\right)$.
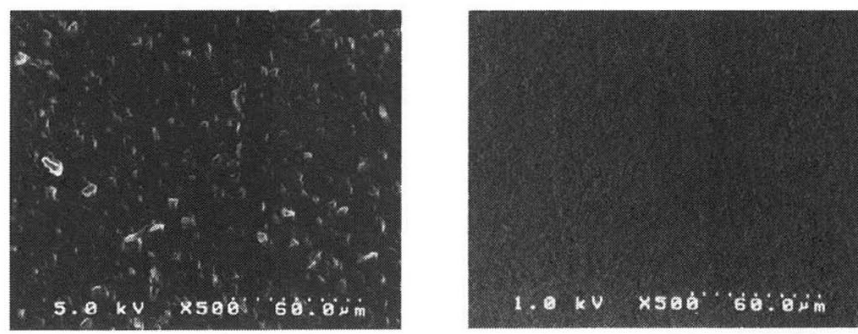

Fig. 3 Scanning electron micrographs of the sensor surface. (A) Without coating (silver electrode) and (B) after epoxy resin coating. Film thickness, $1.5 \mu \mathrm{m}$.

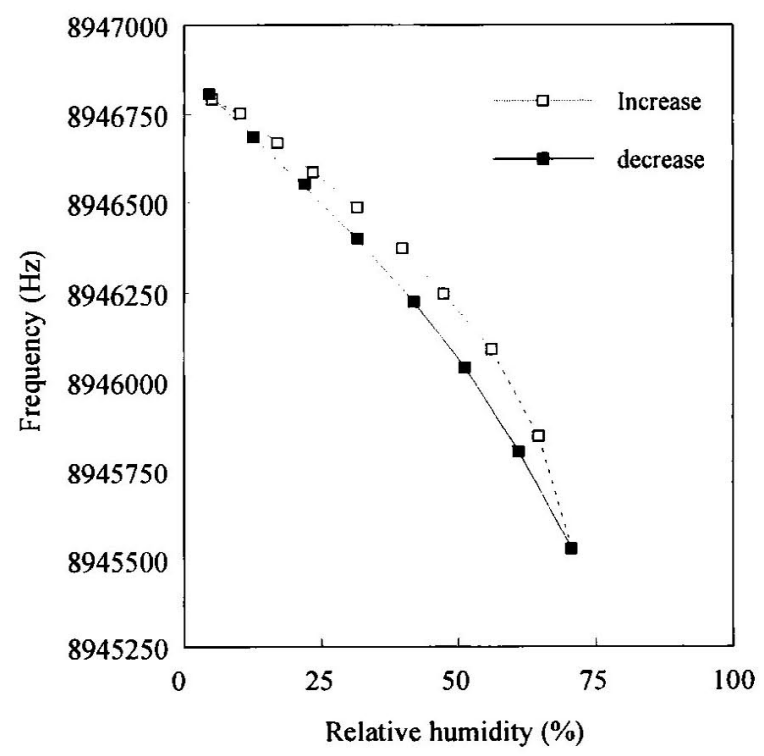

Fig. 4 Hysteresis behavior of frequency after exposure to the humidified air up to $70 \%$ at $20^{\circ} \mathrm{C}$.

Film thickness, $1.5 \mu \mathrm{m}$.

\section{Results and discussion}

\section{1 Epoxy resin coatings}

Scanning electron micrographs (Figures $3 \mathrm{~A}, \mathrm{~B}$ ) before and after formation of epoxy resin coating show silver grains on the sensor surface prior to coating, but not afterwards. The change in resonant frequency for this sample was about $50000 \mathrm{~Hz}$. If the density of the resin is taken as $1 \mathrm{~g} / \mathrm{cm}^{3}$, then the average thickness of

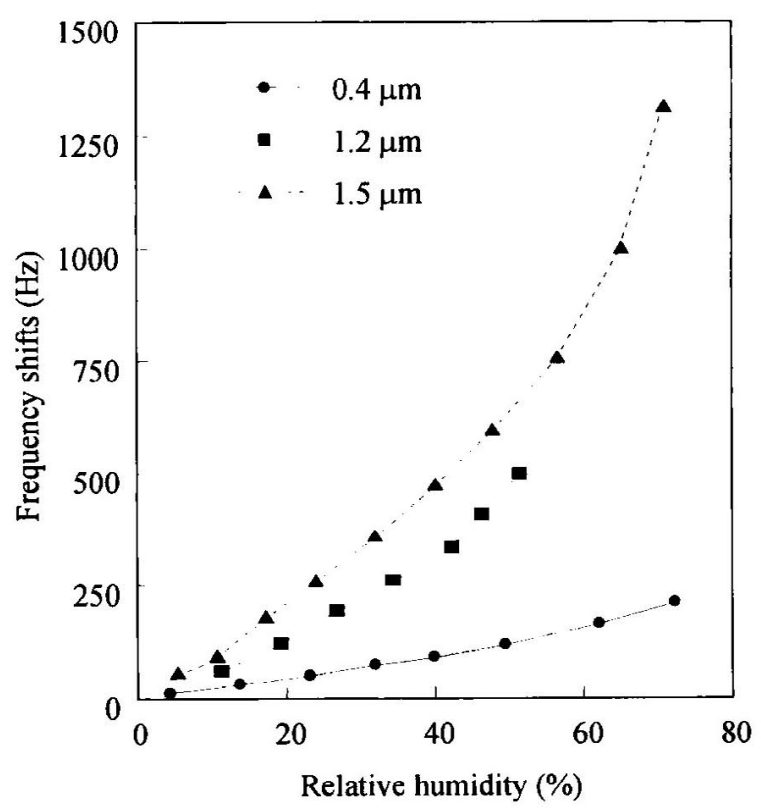

Fig. 5 Influence of the film thickness on relationships between frequency shifts and relative humidity at $20^{\circ} \mathrm{C}$.

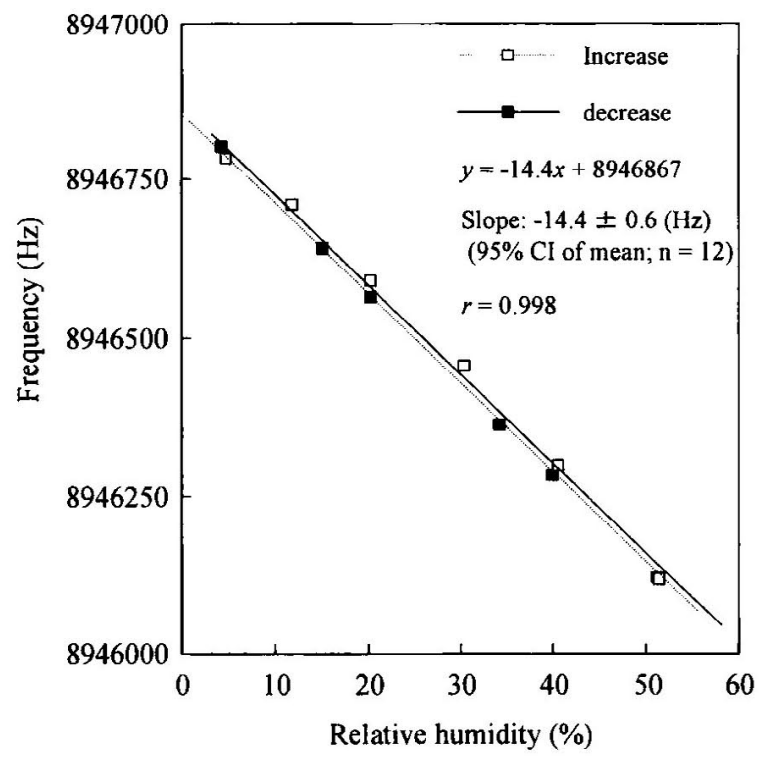

Fig. 6 Resonant frequency versus relative humidity up to $50 \%$ at $20^{\circ} \mathrm{C}$.

Regression analysis shows that resonant frequency hysteresis is absent for RH values between $0-$ $50 \%$. The derived regression function, $95 \%$ confidence interval $(\mathrm{CI})$ of the slope and the correlation coefficient $(\mathrm{r})$ are given. Film thickness, $1.5 \mu \mathrm{m}$. 
the coating was $1.5 \mu \mathrm{m}$ for each side as calculated using equation (1).

\section{2 Sensor sensitivity}

The relationship between $\mathrm{RH}$ and resonant frequency of the epoxy resin coated sensor is shown in Figure 4. With increasing $\mathrm{RH}$, the resonant frequency steeply decreased above $50 \% \mathrm{RH}$, and hysteresis between ascending and descending curves was observed. Film thickness influences the relationship between frequency shifts and RH (Figure 5). The film thicknesses of the samples calculated with equation (1) were 1.5, 1.2 and $0.4 \mu \mathrm{m}$ per side, respectively. As the thickness of epoxy resin coating increased, so did the sensor sensitivity. These results indicated that not only adsorption to the surface but also absorption in the coating occurred. Therefore, it is likely that the water molecules within the coating could not be desorbed within our measuring

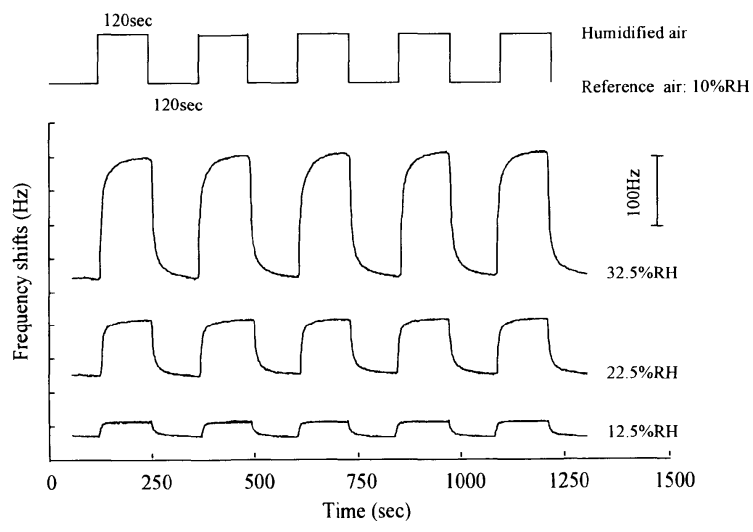

Fig. 7 The responsiveness of quartz crystal humidity sensor to repeated humidity changes.

Film thickness, $1.5 \mu \mathrm{m}$.

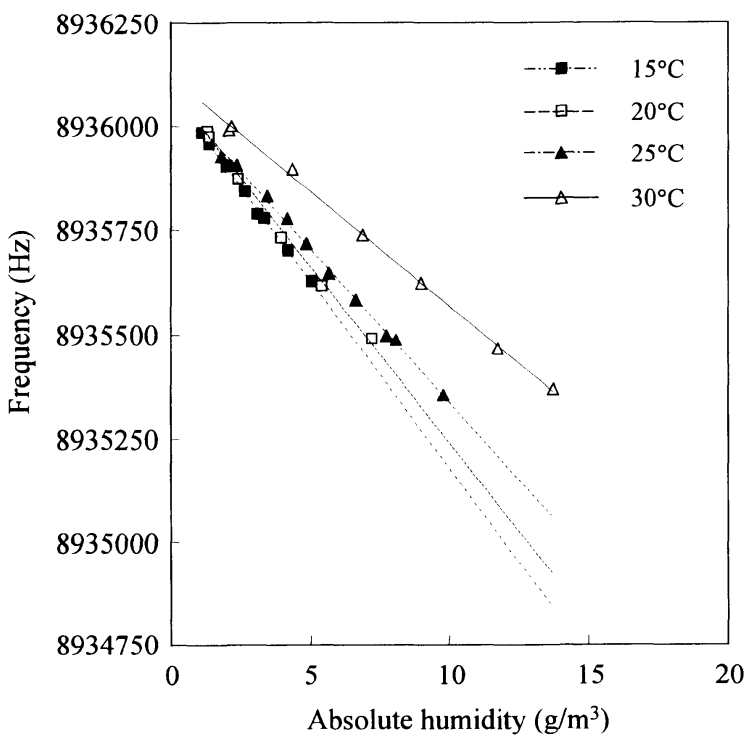

Fig. 8 Influence of temperature on the sensitivity to absolute humidity.

Lines represent best fit regression results. Film thickness, $1.5 \mu \mathrm{m}$. time and contributed to the hysteresis observed.

At $20^{\circ} \mathrm{C}$, the relationship between $\mathrm{RH}$ and resonant frequency was linear from 0 to $50 \% \mathrm{RH}$, and hysteresis was not observed (Figure 6). The slope of the regression line is defined as sensor constant $k(\mathrm{~Hz})$, having the value with its $95 \%$ confidence interval of $-14.4 \pm 0.6$ $(n=12)$. This means that the resolution of the sensor is less than $0.1 \%$ RH using a frequency counter with a resolution of $1 \mathrm{~Hz}$. The difference in relative humidity between outlet and inlet gases is given as follows:

$$
\Delta H=\frac{\Delta F}{k}
$$

where $\Delta F$ is the shift of frequency $(\mathrm{Hz})$ from that of the reference RH. Then, equation (2) becomes

$$
J=\frac{1}{A} \frac{\Delta F}{k \cdot 100} \rho V
$$

\section{3 Response characteristic}

Figure 7 shows the responsiveness of quartz crystal humidity sensor to repeated humidity changes. Reference air (10\% RH) was replaced by humidified air (12.5, $22.5,32.5 \% \mathrm{RH})$ at $120 \mathrm{sec}$ intervals. The frequency rapidly increased and decreased, returning to initial values, after each exposure. During the repeated humidity jumps, the time to reach steady state was confirmed to be less than $120 \mathrm{sec}$ for both adsorption and desorption processes. The frequency at the steady state remained very stable.

\section{4 Influence of temperature on the sensitivity}

In the range from 0 to $50 \% \mathrm{RH}$, the relationship between the absolute humidity and the resonant frequency of quartz crystal was almost linear from 15 to $30^{\circ} \mathrm{C}$ (Figure 8). The absolute slopes of the regression lines gradually decreased as the measuring temperature increased. Therefore, this humidity sensor has sufficient sensitivity to the absolute humidity when the temperature is controlled within these ranges.

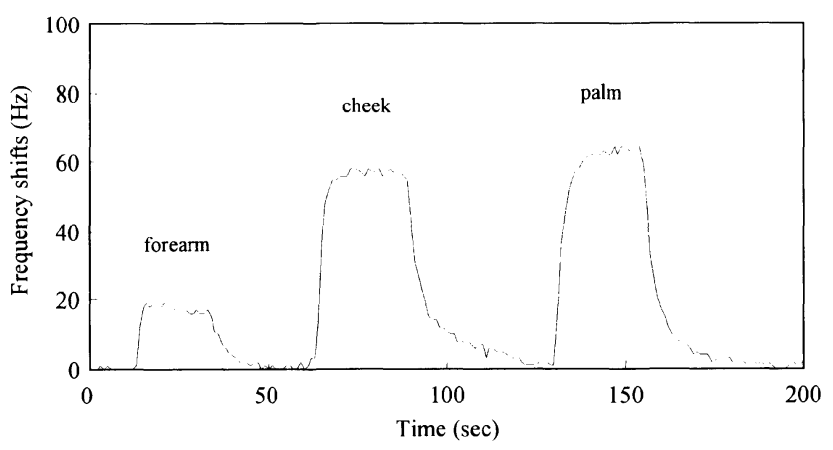

Fig. 9 Frequency shift profiles reflecting water evaporation rates for forearm, cheek and palm of hand.

Relative humidity of the carrier gas was $10 \pm 1 \%$. Resonant frequency shifted steeply soon after opening the shutter and exposure of the skin surface to the carrier gas. After reaching steady state, the humidity sensor was exposed to dry air by closing shutter following which the resonant frequency returned to the baseline. Film thickness, $1.5 \mu \mathrm{m}$. 


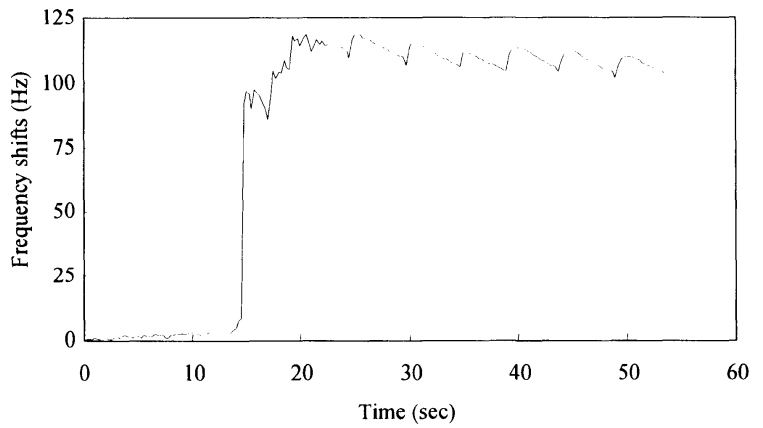

Fig. 10 Frequency shift profile reflecting water evaporation from ocular surface. Oscillations coincide with blinks every $5 \mathrm{sec}$. Relative humidity of the carrier gas was $10 \pm 1 \%$. Film thickness, $1.5 \mu \mathrm{m}$.

\section{5 Measurement of water evaporation rate from human surfaces}

The quartz crystal humidity sensor was used to measure water evaporation rates from human forearm, cheek and palm. The frequency shifts reached steady state within about $60 \mathrm{sec}$ after the shutter was opened (Figure 9), and the time for returning to the baseline after closing the shutter was also very quick. This responsiveness was sufficient to rapidly measure water evaporation rates, an operational feature that will enable its practical use. The rates of water evaporation (mean \pm standard deviation) from the forearm, cheek and palm were $10.7 \pm 0.5,35.0 \pm 1.3$, and $40.2 \pm 1.6 \mathrm{~g} / \mathrm{m}^{2} \cdot \mathrm{hr}$, respectively $(n=10$ for each site). These values and the differences between them are very reasonable and consistent with other studies ${ }^{22,23)}$.

As described above, the probe was adapted to a goggle that fit snugly around the skin of the eye. After achieving steady state, changes in $\mathrm{RH}$ were detected that coincided with blinks of the eye at $5 \mathrm{sec}$ intervals (Figure 10). Therefore, this system has enough sensitivity to evaluate dynamic changes of water evaporation rates from the ocular surface. Based upon the recorded frequency shifts, the calculated rate of water evaporation (mean \pm standard deviation) was $299 \pm 4\left(\mathrm{~g} / \mathrm{m}^{2} \cdot \mathrm{hr}\right)$.

\section{Conclusions}

A highly sensitive humidity sensor was prepared by coating of epoxy resin on an AT-cut quartz crystal surface. In the range from 0 to $50 \% \mathrm{RH}$, the sensor has excellent properties of linearity of resonant frequency, high resolution $(\leq 0.1 \% \mathrm{RH})$, and short time response. Utilizing this technology, a new ventilated chamber type apparatus has been developed to measure the rate of water evaporation from human surfaces. The values of water evaporation rates for forearm, cheek, palm of hand and ocular surface were consistent with previously reported values. Furthermore, at steady state, sensor frequency shifts coinciding with ocular blinks were easily detected. Therefore, this system with an epoxycoated quartz crystal sensor is very useful in measuring water evaporation rates and also in evaluating dynamic changes in rates. Because of its high performance and ease of operation, this system will have applications in clinical use and in the development of cosmetic products.

(Received April 16, 2001 ; Accepted August 8, 2001)

\section{References}

1 ) G. E. Nilsson ; Med. Biol. Eng. Comput., 15(3), 209 (1977)

2 ) D. Spruit ; J. Appl. Physiol., 23 (6), 994 (1967)

3 ) W. H. King; Jr, Anal. Chem., 36, 1735 (1964)

4) W. H. King; Jr, Res. Develop., 20(4), 28 (1969)

5 ) D. T. Gjessing, C. Holm and T. Lanes ; Electron . Lett., 3(4), 156 (1967)

6 ) R. Samuel, A. Kalanidhi, T. N. Ranganathan and M. Kumaravel ; J. Instr. Electronics \& Telecom. Engrs, 22, 208 (1976)

7 ) C. W. Lee, Y. S. Fung and K. W. Fung; Analytica . Chimica. Acta, 135, 277 (1982)

8 ) S. Tahara, J. Kobayashi and S. Oka ; Anal. Chem. Symp. Ser., 17, 405 (1983)

9 ) J. P. Randin and F. Züllig ; Sensor and Actuator, 11, 319 (1987)

10) H. Ito ; Proceedings of the 3rd Sensor Symposium, 169 (1983)

11) H.-T. Sun, Z.-T. Cheng, X. Yao and W. Wlodarski; Sensors and Actuators B, 13, 107 (1993)

12) N. Kurioka, D. Watanabe, M. Haneda, T. Shimanouchi, T. Mizushima, N. Kakuta, A. Ueno, T. Hanaoka, and Y. Sugi ; Catal. Today, 16, 495 (1993)

13) M. Neshkova, R. Petrova and V. Petrov ; Anal. Chim. Acta, 332, 93 (1996)

14) E. Ranucci, P. Ferruti, V. Ferrari, D. Marioli, and A. Taroni ; Macromol. Symp., 109, 89 (1996)

15) E. Radeva ; Sensors and Actuators B, B 44, 275 (1997)

16) E. Radeva, V. georgiev, L. Spassov, N. Koprinarov and St. Kanev; Sensors and Actuators B, B 42, 11 (1997)

17) S. Mintova, S. Mo and T. Bein ; Chem. Mater., 13, 901 (2001)

18) K. Tsubota and M. Yamada; Invest. Ophthamol. Vis. Sci., 33, 2942 (1992)

19) G. Sauerbrey ; Z Phys, 155, 206 (1959)

20) K. K. Kanazawa and J. G. Gordon II ; Anal. Chem. Act., 175, 99 (1985)

21) D. A. Buttry and M. D. Ward;Chem. Rev., 92, 1355 (1992)

22) A. Rougier, C. Lotte, P. Corcuff and H. I. Maibach ; $J$. Soc. Cosmet. Chem., 39, 15 (1988)

23) G. Yosipovitch, G. L. Xiong, E. Haus, L. SackettLundeen, I. Ashkenazi and H. I. Maibach ; J. Invest. Dermatol., 110, 20 (1998) 